\title{
Patenting the Life Sciences at the European Patent Office
}

\author{
Christina Gates \\ Tomkins IP, Dublin 6, Ireland \\ Correspondence: cgates@tomkins.com
}

The European patent system is very much like those of the United States and other major countries. Patent applications can be filed as a first filing, as a priority application, or as a national phase of a Patent Cooperation Treaty application. The applications are searched, rigorously examined, and ultimately granted, with the time periods varying somewhat depending on the application type. The object of this article is to highlight some of the differences between the U.S. and European systems, particularly as they relate to life sciences.

U nlike the U.S. patents statute, the European Patent Convention (EPC) does not attempt to define what constitutes patentable subject matter. Instead, it tells us what are not to be regarded as inventions. The invention must lie in a field of technology, it must concern a technical problem, and it must have technical features. Thus, a technical character is essential for there to be invention, but rather unhelpfully the EPC does not include a definition of the word "technical." Most of the European Patent Office's (EPO) case law on the meaning of "technical effect" relates to the fields of computing, software, and business methods, where lack of technical effect is frequently encountered as an objection; it is much less common in the life sciences.

\section{PATENTABLE SUBJECT MATTER}

Article 52 of the EPC defines patentable inventions in a negative sense:
(1) European patents shall be granted for any inventions, in all fields of technology, provided that they are new, involve an inventive step and are susceptible of industrial application.

(2) The following in particular shall not be regarded as inventions within the meaning of paragraph (1):

(a) discoveries, scientific theories and mathematical methods;

(b) aesthetic creations;

(c) schemes, rules and methods for performing mental acts, playing games or doing business, and programs for computers;

(d) presentations of information.

(3) Paragraph (2) shall exclude the patentability of the subject-matter or activities referred to therein only to the extent to which a European patent application or European patent relates to such subject-matter or activities as such.

Under Article 53 of the EPC, European patents shall not be granted in respect of:

Editors: Salim Mamajiwalla and Rochelle Seide

Additional Perspectives on Intellectual Property in Molecular Medicine available at www.perspectivesinmedicine.org

Copyright (C) 2014 Cold Spring Harbor Laboratory Press; all rights reserved; doi: 10.1101/cshperspect.a020792

Cite this article as Cold Spring Harb Perspect Med 2014;4:a020792 
C. Gates

(a) Inventions the commercial exploitation of which would be contrary to "ordre public" or morality; such exploitation shall not be deemed to be so contrary merely because it is prohibited by law or regulation in some or all of the Contracting States;

(b) Plant or animal varieties or essentially biological processes for the production of plants or animals; this provision shall not apply to microbiological processes or the products thereof;

(c) Methods for treatment of the human or animal body by surgery or therapy and diagnostic methods practised on the human or animal body; this provision shall not apply to products, in particular substances or compositions, for use in any of these methods.

Thus, as regards life sciences, the most relevant exclusion is the exclusion of new discoveries. Finding a new property of a product is considered to be a mere discovery, but if that property can be put to use in some way, then this is considered to be an invention. For example, it is sometimes the case that an inventor determines how a compound actually works and thus now understands the effect of the compound on a particular metabolic process; this knowledge would be patentable if it can be used to treat a particular disease. For example, upon determining that a known compound had antibacterial properties, the use of the compound as an antibiotic would be patentable. However, if the inventor determines a property of a known substance in a known use, then the knowledge is considered to be a discovery - the inventor has simply discovered how the compound works. It is, however, accepted that determining a new property of a known compound, where that property provides a new technical effect such as the ability to treat a disease, renders the new use patentable.

Article 53 of the EPC also defines some exceptions to patentability. One of these is plant or animal varieties or, essentially, biological processes for the production of plants or animals. Thus, plants and animals themselves are patentable under the EPC, at least in principle, and only varieties are unprotectable. Essentially, biological processes for producing plants and animals such as, for example, traditional breeding methods that involve natural phenomena, such as crossing or selection, are not considered patentable, but microbiological processes are. Many EPC contracting states have special legal protection for plant varieties at the national level, and so there are other mechanisms for protecting plant varieties. A distinction is thus made between a claim encompassing plant varieties and a claim directed to a specific variety. Thus, a transgenic or genetically modified plant or animal is patentable if the invention is not confined to a particular plant or animal variety, but is more widely applicable. In the Harvard/ OncoMouse case (T 19/90), claims were allowed to genetically modified rodents and nonhuman mammals, which are not animal varieties. Following opposition, the EPO Board of Appeal ( $\mathrm{T}$ 315/03) allowed claims to transgenic mice but not rodents generally, arguing that the need of mankind to treat disease had to be balanced with avoiding suffering to animals and protecting against uncontrolled dissemination of unwanted genes.

Also excluded from patentability are methods of treatment of the human or animal body by surgery or therapy and diagnostic methods practiced on the human or animal body. Products that could be used in any of these methods are, however, patentable, as are methods carried out on tissue samples or fluids removed from the body. The thinking behind this provision is that medical practice should not be encumbered by patent law, but as we all know, that is not the case. It is only medical methods that are unprotectable; cosmetic methods are protectable. The aim of the article is to exclude curative or prophylactic treatments from patent protection, but not noncurative treatments such as cosmetic treatment, termination of pregnancy, castration, etc. Although determining whether the treatment needs to be carried out by a physician is useful in determining whether the treatment is curative, the purpose and ultimate effect of the method are much more important. The relief of pain, discomfort, or incapacity is considered therapy even if it does not actually cure the underlying condition. Some of the tougher de- 
cisions on patentability under this section are the findings that a method of cleaning teeth to remove plaque and a method of controlling ectoparasites on pigs by localized application of a pesticide to the pig's body are unpatentable.

Treatment by surgery can be defined as a physical intervention in the human or animal body, the purpose of which is to promote the health and maintain the life of that body. However, case law has indicated that treatment by surgery is meant to mean curative treatments rather than methods, such as, for example, removing excess hair from the body, which is not considered to be a curative treatment. Other case law has defined surgery as involving an invasive step that represents a substantial physical intervention on the body and that requires professional medical expertise. A claim that comprises one surgical step is excluded from patentability even if all of the steps are not surgical in nature.

Treatment by therapy is described as any treatment that is designed to cure, alleviate, remove, or lessen the symptoms of a disease or the prevention or reduction in the possibility of contracting a disease or disorder. Thus, the relief of pain, discomfort, or incapacity is considered to be a therapeutic method. Case law has established that prophylactic treatment is therapeutic in nature because it is directed to the maintenance or restoration of health. Thus, a claim is not allowable if it includes even one feature defining a physical action that constitutes a method of treatment by therapy.

Diagnosis has been defined as the determination of the nature of a medical or veterinary medical condition intended to identify or uncover a pathology. A claim is considered to relate to a diagnostic method only if it includes all steps necessary to make a diagnosis. If one step is omitted, it is considered that there is merely an intermediate finding that is of diagnostic relevance. Furthermore, for the diagnostic method to be practiced on the human or animal body, each of the technical method steps must be performed in that way. The presence or absence of a medical practitioner is not relevant.

Article 54 deals with known substances or compositions for use in methods of treatment or diagnosis and with second or subsequent uses of known substances or compositions for use in such methods. Such uses are patentable under the EPC provided they do not form part of the prior art. The claims have to be formulated in a particular format: "Compounds/substances/compositions of formula $\mathrm{X}$ for use as an active pharmaceutical substance" is used for the first medical indication, and the format "Substance $\mathrm{X}$ for use in the treatment of disease $Y$ " is used for second and subsequent medical indications.

\section{THE EFFECT OF THE EUROPEAN UNION BIOTECHNOLOGY DIRECTIVE}

Much of the case law of the EPO in the life sciences sphere in recent years has been influenced by the Biotechnology Directive of the European Community (formerly known as the European Union or EU). The EPO is not a Community organization: A number of countries are party to the EPC but are not members of the European Community. However, the EPO chose to incorporate the directive into its practice. To do otherwise would have caused enormous confusion for patent practice in this field, with there being substantial differences between what the EPO would allow and what was considered allowable by various national patent offices.

A directive is defined as a legal text drafted by the European Community that links the member states as to the results to achieve and allows them freedom to implement it in the way they choose. The directive on the protection of biotechnological inventions entered into force in July 30, 1998. Its genesis has been particularly tumultuous, and its drafting difficult. The EU directive clarifies the situation regarding patentability of inventions involving plants and animals, indicating that such inventions shall be patentable if the technical feasibility of the invention is not confined to a particular plant or animal variety. The human body at the various stages of its formation and development is not considered patentable, nor are processes for cloning human beings, processes for modifying the germline genetic identity of human beings, the use of human embryos for industrial or 
commercial purposes, or processes for modifying the genetic identity of animals that are likely to cause them suffering without any substantial benefit to man or animal.

Moreover, a patent cannot be granted for immoral inventions or inventions that are contrary to public policy. This section was first applied, in the EPC, in the OncoMouse case in 1989, as mentioned above. The EPC chose a utilitarian approach to this requirement, and balanced the suffering inflicted on animals as well as the harm caused to the environment with the usefulness of the invention to mankind.

The Biotechnology Directive also gave farmers a particular right that limits the monopoly of a patent holder. According to this provision, when there has been a sale or any other commercialization of a plant-propagating material to a farmer, the latter is allowed to use the products of his harvest for propagating or multiplying them. This means that the farmer would have the right to keep some seeds he has produced to sow crops in the following year. The same provision was provided for animal breeders. According to the directive, the farmer can freely reproduce the protected animals if and only if he does not sell them afterward. Although the patent holder cannot protest against the reproduction of the said animals, he or she can ask for a fair compensation from their commercialization.

The incorporation of the EU directive into the EPC strengthened the practice of the EPO in biotechnology while putting greater focus on ethical considerations. For example, the directive affirmed that isolated biological material is patentable even if it has occurred previously in nature. It also confirmed that plants or animals are patentable if the technical feasibility of the invention (e.g., a genetic modification) is not confined to a particular plant or animal variety. Furthermore, an invention relating to gene sequences can be patented as long as the industrial application of the sequence is disclosed in the application and all other patentability criteria are fulfilled.

In addition to the provisions of the EPC and the EU directive, the case law of the EPO's Technical Boards of Appeal and the decisions of its
Enlarged Board of Appeal (EBoA) form a further source of guidance when considering the patentability of biotechnological inventions under the EPC.

A landmark ruling on stem cell cultures was issued in November 2008. In the WARF/ Thomson case (G 2/06), the Enlarged Board of Appeal decided that under the EPC it is not possible to grant a patent for an invention that necessarily involves the use and destruction of human embryos. The EBoA stressed, however, that its decision did not concern the general question of human stem cell patentability.

In a similar manner, the Court of Justice of the EU ruled in 2011 in the Brïstle case (C-34/ 10) that Article 6(2)(c) of the EU directive excludes from patentability an invention that presupposes the destruction of a human embryo irrespective of the point in time at which such destruction takes place.

With regard to plant-related inventions, the EBoA ruled in the "melon patent case" (G 1/98) that plants are in principle patentable if the technical teaching of the invention is not limited to a specific plant variety or varieties. In 2010, the EBoA decided, in what is referred to as the "broccoli and tomato case" (G 2/07 and G 1/ $08)$, that a process for the production of plants comprising the steps of crossing and selection is excluded from patentability even if it contains an additional step of a technical nature, such as the use of molecular genetic markers. The EBoA has been asked to clarify whether the products of such processes (i.e., plants or fruits) are also excluded from patentability. The referrals are pending as cases G 2/12 and G 2/13.

\section{NOVELTY}

Under the EPC, an invention is considered to be new if it does not form part of the state of the art. The state of the art is defined as everything that is made available to the public by written or oral description, by use, or in any other way before the filing date of the application. This is considered to be an "absolute" novelty test. The interpretation of the state of the art is broad enough to cover any form of public disclosure, including poster presentations, talks at scientific confer- 
ences, or any general discussion wherein the inventor may disclose how an invention works. To destroy novelty, it is only required that the public has access to the information; it is not necessary to show that any individual actually did access the information. Thus, placing a book or manuscript on a library shelf, even if we could show that no one had ever actually looked at it, would be sufficient to destroy novelty. In addition, the language of the information is irrelevant. Similarly, if a product is sold and the product could be analyzed to determine the invention, then this is a public disclosure. In a circumstance in which the information disclosed is bounded by an obligation of confidentiality, then it is not considered to be available to the public. Confidentiality need not be a written agreement; provided that the parties understood it to be secret, even tacitly and without a written contract, then the information is not publicly disclosed.

The fact that it is the author's own publication does not prevent the disclosure from being considered to be novelty-destroying, and it is thus important that authors ensure that their patent applications are filed before there is any possibility of Internet disclosure of a submitted journal article or a presentation at a conference.

Perhaps rather surprisingly to U.S. eyes, the content of European patent applications as filed becomes part of the state of the art from the date of filing or from the priority date for novelty purposes, but not for inventive step purposes. Thus, an application that is filed before another but published afterward is novelty-destroying. Clearly, therefore, an applicant's own earlier application may form relevant prior art for his or her later application. This applies only to European applications, and not to national applications filed in Europe, because the EPO cannot readily obtain those documents for searching purposes.

There are a number of disclosures that are considered to be nonprejudicial. The EPC does not allow a grace period prior to the filing of a patent application during which an inventor may disclose the invention without that disclosure being considered state of the art. The only circumstances in which a prior disclosure is not considered prior art is if that disclosure occurred in the 6 months preceding the filing of a European application and if it was due to an abuse of the applicant's legal rights or if the invention was displayed at an international exhibition. That exhibition has to be one that falls within the terms of the convention on international exhibitions, which was last revised in 1972. It is important to note that it is the date of filing and not the priority date that is relevant here to the calculation of the 6-month period. Thus, an abusive disclosure or disclosure at a recognized exhibition is not considered prior art if the patent application is filed at the EPO within 6 months. It is not sufficient to file a national application outside the EPO. It would, however, be possible to file a Patent Cooperation Treaty application designating the EPO to satisfy these requirements, because an international application, for which the EPO acts as a designated office, is deemed to be a European application.

In assessing whether abuse has taken place, it is necessary to show an actual intent to harm or actual knowledge that harm would be a result of the action taken. Thus, a mistake is not correctable, but abuse is.

There are relatively few exhibitions to which this rule applies, but it is important that on filing the European application a statement and a certificate identifying the relevant exhibition is filed at the same time.

\section{INVENTIVE STEP}

Under the EPC, an invention is considered as involving an inventive step if, on review of the state of the art, it is not obvious to a person skilled in the art how to make the invention. Thus, any test of inventive step requires an evaluation of the prior art. Clearly, the greater the number of prior art documents that have to be combined, the more likely it is that an inventive step can be acknowledged. The EPO has developed a procedure, the so-called problem and solution approach, that is used for characterizing an invention and assessing an inventive step from the perspective of the skilled person. It is therefore necessary to characterize the skilled 
person. A skilled person is generally an ordinary practitioner having the common general knowledge of his or her specific technical field. In certain circumstances, the skilled person may actually be a team of individuals. The skilled person is considered not to be creative, to have no imagination, and to be familiar with the established prejudices of his or her field. He or she has no inventive capability. The skilled person is also considered to have access to the state of the art in full. To combine documents, however, a skilled person would have to have a reasonable expectation of success.

The problem and solution approach has three stages.

1. Identify the closest prior art.

2. Establish the objective technical problem in view of the closest prior art.

3. Starting from the closest prior art and the objective technical problem, consider whether the solution provided by the invention would have been obvious to the skilled person at the date of filing of the application.

The closest prior art is the combination of features disclosed in a single reference that is the most promising starting point for developing the invention. So the reference should be directed to an object similar to the invention or belong to a similar or closely related field. It therefore requires the fewest possible modifications to arrive at the claimed invention and ideally should be attempting to solve a similar technical problem.

Then the invention is compared with the closest prior art and the distinguishing features are identified. The "objective technical problem" is the task of modifying the closest prior art to provide the technical effects that these distinguishing features provide over the closest prior art. The objective technical problem need not be the same as that described in the application but can be reformulated if necessary as long as the effect relied upon is derivable from the application as filed.

In the third stage, it is necessary to determine if the skilled person faced with the objective technical problem would develop the closest pri- or art in the way the invention does. It is usually necessary to identify additional prior art to see if it would prompt the skilled person to adapt the closest prior art to arrive at the invention. The more documents that have to be combined with the closest prior art, the more likely there is to be an inventive step.

In some cases, the prior art discloses a different solution to the technical problem than that provided by the invention under examination. In that case, the objective technical problem can be considered to be the provision of an alternative solution to the problem and an inventive step may be acknowledged.

\section{ALLOWABILITY OF AMENDMENTS}

The other test that the EPO carries out in a way that distinguishes it from patent offices in many other (of the) jurisdictions is in determining the allowability of amendments to an application during prosecution. A European patent application, or indeed a granted European patent, may not be amended in such a way that it contains subject matter that extends beyond the content of the application as filed. In other words, an applicant cannot improve his or her position by adding subject matter that was not disclosed in the original application. The EPO uses the socalled disclosure test for determining whether or not an amendment extends the subject matter. So an amendment is not allowed if the amendment results in the skilled person being presented with information that was not directly and unambiguously derivable from the whole content of the application as filed. Alteration or excision of text, as well as the addition of further text, may introduce new subject matter. Furthermore, deletion of a feature from an independent claim will be unallowable if that feature was originally presented as an essential feature of the invention. The EPO has the concept of an "intermediate generalization." When a feature in isolation from an embodiment in the description is added to a claim as filed, the amended claim forms an intermediate generalization, that is, a generalization of the embodiment intermediate the claim as filed and the embodiment. Limitation to an undisclosed intermediate gen- 
Patenting the Life Sciences at the EPO

eralization is possible only if the proposed words of limitation can be found as at least an inherent feature of the original specification.

In addition, a granted European patent may not be amended in such a way that the protection conferred by the patent is extended. Sometimes deletion of a term or of a feature may result in an extension of the patent protection. An amendment made during examination that introduces a limiting feature but at the same time extends the subject matter of the application as filed may not be deleted after grant because deletion of the amendment may result in extension of the protection conferred by the patent. This is known as the Article 123 trap, and either way the patent is considered invalid. It is no defense that the examiner allowed the original amendment. This is the reason that it is so important to determine the exact basis in the application as filed for any amendment made to a European application during prosecution.

\section{THE EUROPEAN PATENT SYSTEM}

As will be apparent from the foregoing, the European patent system involves search and examination in the same way other jurisdictions do. One of the major differences in the European system emerges on grant because the patent is applied for and granted for more than one legal jurisdiction. It makes sense to file a European patent application rather than national applications when protection is sought in at least four European countries, as the costs are likely to be lower than for four national applications.

Once the patent is granted, the patentee can choose to bring the patent into effect in all or a limited number of the countries originally designated. This process, known as validation, involves payment of fees and the furnishing of translations either of the entire specification or just the claims in each jurisdiction, with the formal requirements varying from country to country. Thus, on grant, the European patent becomes a bunch of national patents, which are then maintained separately by payment of renewal fees and which are enforceable before the national courts rather than as a single European patent that is centrally enforceable.

\section{OPPOSITION}

Another advantageous feature of the European patent system is that it allows for opposition to granted patents within 9 months of grant. This provides an opportunity for other parties to make prior art known to the EPO or to raise other objections to a case and ultimately has the effect of ensuring that most patents granted by the EPO are valid and enforceable. It can be seen as a quality control mechanism.

Once a European patent is granted, it becomes open to opposition for a 9-month period following grant. Any party may oppose a patent on the following grounds.

1. The subject matter of the European patent is not patentable because it (a) is not new, (b) does not involve an inventive step, (c) is not susceptible of industrial application, (d) is not regarded as an invention under Article 52 mentioned above, or (e) is not patentable under Article 53 as described above.

2. The European patent does not disclose the invention in a manner sufficiently clear and complete for it to be carried out by a person skilled in the art.

3. The subject matter of the European patent extends beyond the content of the application as filed or, if the patent was granted on a divisional application or on a new application in respect of the invention by the person adjudged in a final decision to be entitled to the grant of a European patent (i.e., if there was an ownership dispute), beyond the content of the earlier application as filed.

Certain matters do not constitute grounds for opposition: that national rights of an earlier date exist that put the patentability of the invention in question; that the proprietor of the patent is not entitled to the European patent; that the subject matter of the patent lacks unity; that the claims are not supported by the description (unless it is also argued that the claims are so broadly worded that the description in the specification does not sufficiently disclose the subject matter); that the form and content of the description or drawings of the patent do not comply with the provisions as to formal 
requirements as set forth in the rules; or that the designation of the inventor is incorrect. Nor does the simple allegation that priority has been wrongly claimed constitute a ground for opposition. However, the matter of priority must be subjected to a substantial examination in the course of opposition proceedings if prior art is invoked as a ground for opposition as the priority date is likely to be of decisive importance.

Once the notice of opposition is examined for admissibility and found acceptable, the patentee is informed of the opposition and given a chance to file submissions and, if appropriate, amendments to the claims. A number of sets of claim amendments may be filed of either successively narrowing scope or even alternative wording to overcome the various grounds of opposition. The opposition division of the EPO considers the issues and generally summons the parties to oral proceedings, where the issues are discussed, any amendments filed are considered, and a decision on maintenance of the patent is made. Either party can appeal the decision made by the opposition division to the Board of Appeal, where essentially the procedure is repeated and the decision made final.

\section{LIMITATION AND REVOCATION PROCEEDINGS}

In European patent law, the limitation and revocation procedures before the EPO are postgrant, ex parte, administrative procedures allowing any European patent to be centrally limited by an amendment of the claims or revoked, respectively. These two procedures were introduced in the recently revised text of the EPC, that is, the so-called EPC 2000, which entered into force on December 13, 2007.

Previously, the only possibility for the proprietor of a European patent to voluntarily limit the scope conferred by its patent (e.g., to strengthen the patent in view of some newly discovered prior art documents and/or in advance of envisaged litigation) was to request such limitation at the national level in each country, that is, before the national patent of- fices or competent courts of the contracting states, if permitted.

Limitation proceedings enable patentees to narrow down the protection conferred by a patent, post-grant, by means of a simple, quick, and inexpensive administrative procedure. For example, it may be necessary to limit a granted patent if, because of prior art that was not known during the examination proceedings or prior national rights not taken into account in these proceedings, the extent of the protection conferred is too great. Using the limitation procedure, patent proprietors may themselves reduce the extent of the protection claimed in a manner that is binding, and thus generally preclude disputes over the validity of a patent. The request may be filed at any time throughout the entire term of the European patent. According to the Guidelines for Examination at the EPO, the request can even be filed after expiry of the patent. However, the request may not be filed while opposition proceedings are pending.

Upon approval of the amended claims by the examining division, a fee must be paid and the amended claims must be translated in the two official languages of the EPO other than the language of the proceedings, within a period of 3 months. In addition, complete translations of the patent as limited, in an official language of some countries, may need to be filed in the countries prescribing it.

The request for limitation or revocation has effect $\mathrm{ab}$ initio. This means that the limitation or revocation has effect as of the filing date of the patent application that led to the patent, rather than from the date of the decision on the limitation or revocation.

Decisions of the examining divisions in limitation and revocation proceedings are open to appeal.

\section{CONCLUSION}

Overall, the European patent system provides a system to obtain patent protection in almost 40 European countries on the basis of a single application. European patents are granted in a centralized and thus cost-effective and time- 
saving procedure. Every European patent undergoes rigorous substantive examination and can be obtained for countries that otherwise have "registration-only" systems, thus providing strong protection throughout Europe. The term, scope of protection, binding text, and grounds for revocation of European patents are the same for all contracting states to the EPC, which gives certainty both to patentees and to their competitors.

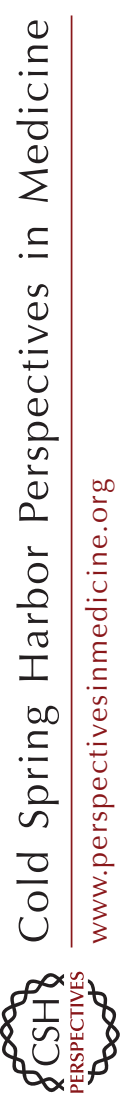




\section{$\& \mathrm{CSH} \&$ Cold Spring Harbor \\ $\stackrel{\text { PERSPECTTMES }}{\longrightarrow}$ Perspectives in Medicine}

\section{Patenting the Life Sciences at the European Patent Office}

Christina Gates

Cold Spring Harb Perspect Med 2014; doi: 10.1101/cshperspect.a020792 originally published online October 23, 2014

Subject Collection Intellectual Property in Molecular Medicine

Patentability of Stem Cells in the United States Sarah E. Fendrick and Donald L. Zuhn, Jr.

Inventorship and Authorship Antoinette F. Konski and Linda X. Wu

The Patentability of Stem Cells in Australia Jenny Petering and Prue Cowin

Impact of America Invents Act on Biotech Intellectual Property

Amanda Murphy, Michael Stramiello, Jonathan Stroud, et al.

Introduction to Intellectual Property: A U.S.

Perspective

Amanda Murphy, Michael Stramiello, Stacy Lewis, et al.

The Role of Regulatory Agencies and Intellectual Property: Part I

Kevin E. Noonan

Canada's Patented Medicines (Notice of Compliance) Proceedings and Intellectual

Property

Henry Bian and Conor McCourt

Patentability of Genes: A European Union

Perspective

Paul Cole
The Impact of Myriad on the Future Development and Commercialization of DNA-Based Therapies and Diagnostics

Michele Wales and Eddie Cartier

Protecting Traditional Knowledge Related to

Biological Resources: Is Scientific Research

Going to Become More Bureaucratized?

Prashant Reddy and Malathi Lakshmikumaran

Protecting Trade Secrets in Canada

Noel Courage and Janice Calzavara

Inherent Anticipation in the Pharmaceutical and

Biotechnology Industries

Michael Goldman, Georgia Evans and Andrew Zappia

The Role of Regulatory Agencies and Intellectual

Property: Part II

Kevin E. Noonan

Baseball Bats and Chocolate Chip Cookies: The Judicial Treatment of DNA in the Myriad Genetics Litigation lan Binnie and Vanessa Park-Thompson

The Impact of Myriad and Mayo: Will

Advancements in the Biological Sciences Be

Spurred or Disincentivized? (Or Was Biotech

Patenting Not Complicated Enough?) Jennifer Gordon

Trade Secrets in Life Science and Pharmaceutical Companies

Tara Nealey, Ronald M. Daignault and Yu Cai

For additional articles in this collection, see http://perspectivesinmedicine.cshlp.org/cgi/collection/ 